\title{
The Effect of Enzyme Therapy on Skin Symptoms and Immune Responses in Patients with Dermatitis Herpetiformis
}

\author{
Agnieszka Zebrowska ${ }^{1}$, Hugh J. Cornell ${ }^{2}$, Finlay A. Macrae ${ }^{3}$, Anna Sysa-Jedrzejowska ${ }^{1}$, Elzbieta Waszczykowska ${ }^{1}$, \\ Teodor Stelmasiak ${ }^{4}$ \\ ${ }^{1}$ Department of Dermatology and Venereology, Lodz Medical University, Lodz, Poland \\ ${ }^{2}$ School of Applied Science, RMIT University, Melbourne, Victoria, Australia \\ ${ }^{3}$ Department of Colorectal Medicine and Genetics, and University of Melbourne Department Medicine, The Royal Melbourne Hospital, \\ Parkville, Victoria, Australia \\ ${ }^{4}$ Glutagen Pty Ltd, Maribyrnong, Victoria, Australia \\ *Corresponding author: finlay.macrae@mh.org.au
}

Received February 16, 2014; Revised May 14, 2014; Accepted May 14, 2014

\begin{abstract}
Background: The aetiology of coeliac disease (CD) has many similarities to that of dermatitis herpetiformis (DH), except that DH lesions are mainly manifested in the skin. Mucosal enzyme deficiency plays an important part in CD pathology. Clinical studies indicated that the gluten exposure in CD could be partly corrected by the use of enzyme supplementation. Objective: Enzyme therapy, using enterically coated tablets containing caricain, was investigated as a means of protecting patients with DH against wheat gluten. Methods: A randomized, placebo-controlled clinical trial was carried out on $20 \mathrm{DH}$ patients in clinical remission. The patients were divided into two groups of 10, one group given a placebo daily and the other the enzyme - containing tablets. Both groups were challenged with $6 \mathrm{~g}$ of gluten daily in a double-blind trial. Symptoms and signs of skin involvement were recorded and graded at the start of the trial, after 7 days and after 14 days. Blood was also taken at the start and after 14 days and assayed for IgA EMA and anti-gliadin antibodies. Results: After 7 days the major features associated with DH were more severe and more common with the placebo compared with enzyme therapy. Before 14 days, seven patients in total, six on placebo, had to withdraw from the trial because of the effects of the gluten challenge whilst 2 patients on therapy developed blisters, erythema and itching. Serological tests indicated that IgA EmA antibodies and anti-gliadin antibodies after 14 days were not affected significantly, but indicated that abnormally high antibodies titers of both types were present in 8 patients at the start of the trial, suggesting the need for enzyme therapy in addition to the normal gluten-free diet for patient well-being. Conclusions: This study supports the use of enzyme supplementation as a safeguard for patients with DH on a nominal gluten-free diet.
\end{abstract}

Keywords: dermatitis herpetiformis, coeliac disease, gluten, caricain, enzyme therapy, IgA endomysial antibodies, antigliadin antibodies

Cite This Article: Agnieszka Zebrowska, Hugh J. Cornell, Finlay A. Macrae, Anna Sysa-Jedrzejowska, Elzbieta Waszczykowska, and Teodor Stelmasiak, "The Effect of Enzyme Therapy on Skin Symptoms and Immune Responses in Patients with Dermatitis Herpetiformis.” International Journal of Celiac Disease, vol. 2, no. 2 (2014): 58-63. doi: 10.12691/ijcd-2-2-7.

\section{Introduction}

Dermatitis herpetiformis (DH) is one of the subepidermal autoimmune bullous diseases characterized by skin and intestinal lesions. Skin lesions include polymorphic eruptions accompanied by severe pruritus. Intestinal lesions are characterized by atrophy of intestinal villi as in coeliac disease resulting from immunological processes.

Dermatitis herpetiformis (DH) and coeliac disease (CD) are both forms of gluten intolerance in which the small bowel is damaged by proteins present in wheat, rye, barley and some varieties of oats [1]. These proteins cause severe damage to the duodenum and jejunum (villous atrophy) and can produce a variety of symptoms such as abdominal pain and cramping, bloating, diarrhoea, nausea and lethargy. The aetiology of $\mathrm{CD}$ has many similarities to that of $\mathrm{DH}$, except that the manifestation of the latter condition is more prominently the formation of a skin rash, blistering and itchiness [2]. DH was described by Duhring in 1884 and named after him [3]. DH is a chronic subepidermal autoimmune bullous disease characterized by skin and intestinal lesions. Skin lesions include polymorphic eruption (papules, vesicles), mainly distributed over the shoulders, elbows, back, buttocks and knees. They are usually symmetric and accompanied by severe pruritus $[4,5]$.

In both conditions gluten is considered to be harmful and a gluten-free diet is mandatory. In addition, patients with $\mathrm{DH}$, similarly to patients with $\mathrm{CD}$ who are not 
adhering to a gluten-free diet, appear to have an increased risk of lymphoma [6]. Dapsone has also been used as symptomatic therapy for $\mathrm{DH}$ [7].

$\mathrm{DH}$ is regarded as a specific cutaneous manifestation of $\mathrm{CD}$ [8]. Intolerance of gluten is the most important feature of both diseases. In $70 \%$ of cases, lesions in the small intestine of DH patients are histologically identical with those observed in $\mathrm{CD}$, although they can be less severe. Even though intestinal villous atrophy is observed in the majority of $\mathrm{DH}$ patients, clinical symptoms of malabsorption are unusual.

Studies on the autoimmune pathogenesis of $\mathrm{DH}$ demonstrated that the key role in this process is the deamidation reaction of a gluten metabolic product, which is carried out by tissue transglutaminase (tTG) [9,10]. IgA endomysial antibodies (IgA EmA) react with tTG, which acts as an autoantigen for those antibodies [11]. DH is normally diagnosed by a blood test for IgA EmA or tissue transglutaminase antibodies [12] and by skin biopsy looking at the pattern of granular IgA deposits [13]. The results of a direct immunofluorescence (DIF) test revealing granular deposits of IgA in the top of the papillae and the presence of circulating IgA antibodies directed against endomysium and/or tissue and epidermal transglutaminase (tTG, eTG) confirm the diagnosis of DH [14]. Skin lesions in DH are histologically characterized by neutrophilic infiltrate leading to destruction of basement membrane zone (BMZ) proteins.

Pathological changes in the small intestine result in development of a "flat mucosa" and subsequent disorders in intestinal absorption $[15,16,17,18]$. Thus one could expect a low degree of disturbed absorption or even its absence, however, patients with $\mathrm{DH}$ periodically present with stomach ache, anaemia and/or diarrhoea. Experimental studies may show disturbed absorption of calcium, vitamin D and trace elements.

Mucosal enzyme deficiency plays an important part in CD pathology [19]. After ingestion of gluten, special enzymes called endopeptidases, to which caricain belongs, are required to complete the digestion of the peptides produced from gluten. If digestion is not completed, these peptides may have a direct toxic action on the cells of the small intestine and invoke immunological reactions that exacerbate the damage. Clinical studies have indicated that the damage caused by gluten exposure in coeliac disease could be partly corrected by the use of enzyme supplementation [20,21]. In vitro evidence suggested that enzyme caricain may be useful as therapeutic agent [22].

With $\mathrm{DH}$, a gluten-free diet is essential in order to prevent the troublesome rash, allow a decrease in the daily dose of sulphones but also to guard against damage to the small intestine. Our preliminary experiment with one DH patient indicated that the effects of a gluten challenge were largely eliminated by the use of an enzyme supplement based on caricain. The aim of the present study is to evaluate the effect of caricain on symptoms and signs of $\mathrm{DH}$ in patients challenged with dietary gluten in comparison with patients treated with a placebo. This study is the first to investigate the use of enzyme therapy in $\mathrm{DH}$.

\section{Materials and Methods}

\subsection{Patients}

Twenty adult (18-70 years of age, 6M, 14F) volunteers with diagnosed $\mathrm{DH}$ in clinical remission maintaining their usual gluten-free diet were selected for the study. Most of these patients were diagnosed 15 to 30 years ago. Five patients had a mild erythema (1 to $3 \mathrm{~cm}^{2}$ ) and one had papules $\left(2 \mathrm{~cm}^{2}\right)$. Diagnosis of DH was established based on earlier clinical presentation and results of histological and immunological examination. The volunteers followed their usual gluten-free diet for the duration of the study. All the patients signed informed consent before entering the study and the study protocol (RNN/12/12/KE) was approved by The Local Ethical Committee of Medical University of Lodz, Poland.

\subsection{Gluten Challenge and Enzyme Administration}

Patients were subjected to a modest gluten challenge consisting of about six grams of gluten daily. Gluten was given in a form of commercial wheat biscuits (e.g. Vitaweat) each containing approximately 0.66 gram of gluten. Three biscuits were taken with breakfast, lunch and dinner. The study design was a randomized double-blind parallel one in which half the group was challenged and given enzyme supplement and the other $10 \mathrm{DH}$ patients challenged and given placebo for the same period of time (two weeks). Two tablets were taken orally with each biscuit meal (six tablets per day). The patients recorded the timing of the appearance of symptoms and grade of the skin lesions on a linear scale of units from 0 to 5 , where 0 = symptoms and/or signs absent, 1 = mild, 3 = moderate, 5 = severe. Itch was recorded on a linear scale of 0 to 10 . The patients had the skin lesions assessed (severity and area) by the supervising investigator. The investigations also included recording of the IgA EmA and antigliadin antibody titres in blood. The Euroimmun IIFT No. FA 1911-1005-1A test kit was employed. Patients who developed symptoms or signs earlier than two weeks stopped the gluten challenge and continued taking the tablets until the end of two week period and completion of the trial. The enzyme supplement was in the form of enterically coated tablet. An enteric coating protected the tablet against stomach acid and delivered its content to the small intestine to support the final digestion of gluten. Each tablet contained $40 \mathrm{mg}$ of caricain, a natural enzyme derived from papaya fruit (Carica papaya) which was sufficient to detoxify approximately 6 g of gluten [22].

\subsection{Statistical Analysis}

The scores for itch and lesions and areas of skin lesions were used to determine if there was a significant difference in each of the skin symptoms and/or signs between enzyme therapy and the administration of the placebo. These differences were subjected to the Dunnett test for estimation of probabilities.

\section{Results}

\subsection{Skin Lesions}

The area of DH skin lesions were significantly attenuated in patients challenged with gluten when on enzyme therapy compared with a placebo capsule. Pruritus showed a non-significant trend to improvement. There 
was a diverse response by patients to gluten challenge, but even after 7 days, 13 patients developed pruritus and/or
DH skin lesions allowing for a comparison across randomized groups. The results are presented in Table 1.

Table 1. Effects of enzyme therapy on clinical features of DH, showing changes in scores (itch and lesions) and area of skin lesions after 7 days of treatment, compared with placebo. The degree of protection (\%P) was also calculated for each particular symptom

\begin{tabular}{|c|c|c|c|c|}
\hline Symptom & $\begin{array}{l}\text { Increase in score on placebo } \\
\text { Mean } \pm \text { sem }\end{array}$ & $\begin{array}{c}\text { Increase in score on enzyme therapy } \\
\text { Mean } \pm \text { sem }\end{array}$ & $\begin{array}{c}\% \\
\text { Protection }\end{array}$ & $\begin{array}{c}\text { Statistical validity: } \mathrm{p} \text { from } \\
\text { Dunnett test }\end{array}$ \\
\hline Itch & $\begin{array}{c}40 \\
4.00 \pm 1.01\end{array}$ & $\begin{array}{c}25 \\
2.50 \pm 0.83\end{array}$ & 38 & 0.10 \\
\hline $\begin{array}{l}\text { Number of skin } \\
\text { Lesions }\end{array}$ & $\begin{array}{c}24 \\
2.40 \pm 0.65\end{array}$ & $\begin{array}{c}7 \\
0.70 \pm 0.67\end{array}$ & 71 & 0.085 \\
\hline Area of skin lesions & $\begin{array}{c}195 \mathrm{~cm}^{2} \\
19.50 \pm 6.00\end{array}$ & $\begin{array}{c}37 \mathrm{~cm}^{2} \\
3.70 \pm 1.28\end{array}$ & 81 & 0.02 \\
\hline
\end{tabular}

Table 2. Numbers of patients affected with clinical features of DH on placebo compared with those affected on enzyme therapy after 7 days of intervention with 10 patients in each category

\begin{tabular}{|c|c|c|}
\hline Symptom or feature & Number of patients affected on placebo & Number of patients affected on enzyme therapy \\
\hline Itch (troublesome) & 7 & 3 \\
\hline Lesions (blisters) & 6 & 1 \\
\hline Area of skin lesions (area $\geq 15 \mathrm{~cm}^{2}$ ) & 6 & 2 \\
\hline
\end{tabular}

Note:

1. Four patients on enzyme treatment were free of itch or lesions compared with 3 on placebo.

2. The highest areas of skin lesions ( 6 patients with area $\left.\geq 20 \mathrm{~cm}^{2}\right)$ were all on placebo.

The numbers of patients affected by gluten on placebo compared with those on enzyme therapy are shown in Table 2. They clearly show that all three DH related parameters were ameliorated on enzyme therapy even whilst being challenged by 6 grams of gluten daily. There were 9 patients without significant skin lesions after 14 days; 6 of these were on enzyme therapy and 3 on placebo.

Although only 13 patients completed the study, it was important to note that 6 of the other 7 patients who withdrew (4M, 3F) were on placebo and could not continue taking the gluten biscuit due to the occurrence of blisters and vesicles over a relatively large area as well as severe itching after 5-7 days from commencement of the study. Enzyme therapy was able to prevent 5 out of 8 patients developing any skin lesions throughout the trial. However, there was one patient who presented with papules at the start of the trial, but in whom none were present after 7 days of enzyme therapy.

\subsection{Effect of Age}

The trial is too small to make a statistically valid conclusion about the effect of age on the manifestation of skin symptoms in $\mathrm{DH}$. The data suggest that most of those affected by the gluten challenge were in the age group 40 48 with less in the $61-76$ age group. As seen before, most patients who developed skin symptoms or lesions were in the placebo group. Within this group there is a suggestion of gender bias with males being more predisposed to manifestation of symptoms. The results are summarized in Table 3.

Antibodies titres also tended to higher $(\geq 160)$ in the lower age groups (26 - 36; 40 - 48). Likewise, higher titres were seen after 14 days in those patients in the placebo group.

Table 3. Clinical features of DH patients of different age groups after a 7 day challenge with gluten

\begin{tabular}{|c|c|c|c|c|c|c|c|}
\hline \multirow{2}{*}{ Age group (years) } & \multirow{2}{*}{ No of patients } & \multicolumn{3}{|c|}{ No affected placebo group } & \multicolumn{3}{|c|}{ No affected enzyme therapy group } \\
\hline & & $\mathrm{II}$ & $\mathrm{L}$ & $\mathrm{A}$ & $\mathrm{I}$ & $\mathrm{L}$ & A \\
\hline $26-36$ & $7\{3 \mathrm{M}, 4 \mathrm{~F}\}$ & $2(2 \mathrm{M})$ & $2(2 \mathrm{M})$ & $2(2 M)$ & $1(\mathrm{~F})$ & $1(\mathrm{~F})$ & 0 \\
\hline $40-48$ & $7\{2 \mathrm{M}, 5 \mathrm{~F}\}$ & $4(2 \mathrm{M}, 2 \mathrm{~F})$ & $3(2 \mathrm{M}, 1 \mathrm{~F})$ & $3(2 \mathrm{M}, 1 \mathrm{~F})$ & $1(\mathrm{~F})$ & $1(\mathrm{~F})$ & 1 \\
\hline $61-76$ & $6(1 \mathrm{M}, 5 \mathrm{~F})$ & $1(\mathrm{~F})$ & $1(\mathrm{~F})$ & $1(\mathrm{~F})$ & $1(\mathrm{~F})$ & 0 & 0 \\
\hline Total & 20 & 7 & 6 & 6 & 3 & 2 & 1 \\
\hline
\end{tabular}

Table 4. Changes in titers of IgA EmA from start of trial to the end at 14 days

\begin{tabular}{|c|c|c|c|c|c|c|c|c|c|}
\hline \multicolumn{5}{|c|}{ Placebo } & \multicolumn{5}{|c|}{ Enzyme therapy } \\
\hline Patient No & Sex & Start & 14 days & Difference & Patient No & Sex & Start & 14 days & Difference \\
\hline 1 & $\mathrm{~F}$ & 10 & 0 & 10 & 2 & $\mathrm{M}$ & 40 & 10 & 30 \\
\hline 4 & $\mathrm{M}$ & 320 & 40 & 280 & 3 & $\mathrm{~F}$ & 40 & 40 & 0 \\
\hline 5 & $\mathrm{~F}$ & 40 & 0 & 40 & 6 & $\mathrm{M}$ & 40 & 10 & 30 \\
\hline 7 & $\mathrm{~F}$ & 40 & 0 & 40 & 8 & $\mathrm{~F}$ & 160 & 160 & 0 \\
\hline 11 & $\mathrm{M}$ & 320 & 320 & 0 & 9 & $\mathrm{~F}$ & 40 & 0 & 40 \\
\hline 13 & $\mathrm{~F}$ & 160 & 40 & 120 & 10 & $\mathrm{~F}$ & 40 & 0 & 40 \\
\hline 16 & $\mathrm{M}$ & 320 & 160 & 160 & 12 & $\mathrm{~F}$ & 160 & 40 & 120 \\
\hline 17 & $\mathrm{~F}$ & 40 & 10 & 30 & 14 & $\mathrm{~F}$ & 10 & 0 & 10 \\
\hline 19 & $\mathrm{M}$ & 160 & 160 & 0 & 15 & $\mathrm{~F}$ & 40 & 0 & 40 \\
\hline 20 & $\mathrm{~F}$ & 320 & 320 & 0 & 18 & $\mathrm{~F}$ & 40 & 0 & 40 \\
\hline Total $(n=10)$ & & & & & Total $(n=10)$ & & & & \\
\hline
\end{tabular}

Note:

1. Differences between titers on placebo and enzyme therapy were not significant $(p=0.302)$.

2. Four out of 10 patients had titers of $\geq 160$ on placebo compared with only one of 10 patients on enzyme therapy

3. Two out of 10 patients on placebo still had titers of 320 after 14 days, compared with zero out of 10 patients on enzyme therapy. 


\subsection{Serology}

High levels of both IgA EmA and antigliadin antibodies were present in several patients at the start of the trial, probably indicating that these patients were not adhering to a strict gluten-free diet. High levels of IgA EmA antibodies $(\geq 160)$ were present in 8 patients and, likewise, antigliadin antibodies $(\geq 160)$ in 11 of the 20 patients with a high degree of correspondence. As it so happened, because of random selection, levels of both types of antibodies were higher at the start with the placebo group compared with the enzyme therapy group, making evaluation of the treatment difficult. (Table 4 and Table 5).
Based on differences between the titres at 14 days and at the start of the trial, Table IV shows that there is a trend for the IgA EmA titres to decrease with patients on enzyme therapy as well as those on placebo. The same types of observations were made with antigliadin antibodies (Table 5).

In regard to titres of IgA EmA after 14 days gluten challenge in patients on placebo compared with those on enzyme therapy, it was noted that the highest titres $(\geq 160)$ were more frequently seen in those on placebo (Table 4). Likewise, titres of antigliadin antibodies were also higher in patients on placebo, where the highest titres $(=320)$ overall were observed (Table 5).

Table 5. Changes in titers of antigliadin antibodies from start of trial to the end at 14 days

\begin{tabular}{|c|c|c|c|c|c|c|c|c|c|}
\hline \multicolumn{5}{|c|}{ Placebo } & \multicolumn{5}{|c|}{ Enzyme therapy } \\
\hline Patient No & Sex & Start & 14 days & Difference & Patient No & Sex & Start & 14 days & Difference \\
\hline 1 & $\mathrm{~F}$ & 10 & 0 & 10 & 2 & $\mathrm{M}$ & 40 & 10 & 30 \\
\hline 4 & $\mathrm{M}$ & 320 & 40 & 280 & 3 & $\mathrm{~F}$ & 160 & 40 & 120 \\
\hline 5 & $\mathrm{~F}$ & 160 & 40 & 120 & 6 & $\mathrm{M}$ & 40 & 40 & 0 \\
\hline 7 & $\mathrm{~F}$ & 40 & 10 & 30 & 8 & $\mathrm{~F}$ & 160 & 160 & 0 \\
\hline 11 & $\mathrm{M}$ & 320 & 320 & 0 & 9 & $\mathrm{~F}$ & 40 & 10 & 30 \\
\hline 13 & $\mathrm{~F}$ & 160 & 40 & 120 & 10 & $\mathrm{~F}$ & 40 & 10 & 30 \\
\hline 16 & $\mathrm{M}$ & 160 & 160 & 0 & 12 & $\mathrm{~F}$ & 160 & 160 & 0 \\
\hline 17 & $\mathrm{~F}$ & 160 & 40 & 120 & 14 & $\mathrm{~F}$ & 10 & 10 & 0 \\
\hline 19 & $\mathrm{M}$ & 160 & 160 & 0 & 15 & $\mathrm{~F}$ & 160 & 160 & 0 \\
\hline 20 & $\mathrm{~F}$ & 320 & 320 & 0 & 18 & $\mathrm{~F}$ & 40 & 10 & 30 \\
\hline Total $(n=10)$ & & & & & Total $(n=10)$ & & & & \\
\hline
\end{tabular}

Note:

1. Differences between titers in patients on placebo and enzyme therapy were not significant $(\mathrm{p}=0.178)$

2. Two out of 10 patients on placebo still had titers of 320 after 14 days compared with zero out of 10 patients on enzyme therapy.

\subsection{Gastrointestinal Symptoms}

In the 11 patients who suffered from lesions, only 3 reported gastrointestinal symptoms (abdominal pain, diarrhoea). Two of these patients were on placebo and one on enzyme therapy. Altogether there were only 6 patients who reported gastro-intestinal symptoms, 3 of whom were on placebo and 3 on enzyme therapy and none of these had any significant skin symptoms.

\section{Discussion}

\subsection{Skin Lesions}

The trial has indicated that, as with $\mathrm{CD}$, there is merit in the use of enzyme therapy for $\mathrm{DH}$ as a means of ameliorating the effects of inadvertent ingestion of gluten. Although it is only a small scale trial, the results of our evaluation of $\mathrm{DH}$ clinical features including itch and particularly lesions (erythema and blisters) and area of skin lesions, showed major differences between their development in patients on placebo and patients on the enzyme therapy. The use of enzyme therapy for CD and the choice of caricain as the effective enzyme appear to be a very promising approach for $\mathrm{DH}$ as it has been for CD. Caricain is able to digest gluten to non-toxic fragments and we have evidence that this prevents immunogenic peptides from damaging the small intestine [22], and as a logical corollary, the skin lesions in $\mathrm{DH}$ patients. It has been obvious in all our investigations that patients have difficulty in adhering to a strict gluten-free diet as the baseline indicators such as tissue transglutaminase and IgA EmA are higher than expected. The gluten-free diet has not been well adopted by DH patients because it is socially restricting and requires constant monitoring [8]. Another important reason for introducing enzyme therapy as a safeguard is because a strict gluten-free diet is quite difficult to maintain at all times [20].

There is an individual threshold of tolerance to gluten in patients with $\mathrm{DH}$ and the clinical features are very diverse in nature. In some patients there are skin lesions without any intestinal symptoms after a gluten challenge, indicating different degrees of gluten sensitivity. Itchiness is the first symptom to develop and can occur without skin lesions. However, all three DH features were evident in 8 volunteers after only 7 days and after that, a number of patients from the placebo group withdrew from the study because of the severity of symptoms. This indicates that the dose of gluten challenge was sufficiently high to differentiate between the two groups. Any further trials would need to consider gluten challenge for only 7 days.

\subsection{Serology}

High titres of IgA EmA at the start in 8 patients indicate a degree of non-compliance with a gluten-free diet. However in 5 of these patients, these titers were lower after 14 days (3 on placebo, 2 on enzyme therapy). We think the measurement of IgA EmA is the more appropriate serologic marker for the studies in the light of previous work [13]. Titres varied widely from one patient to another, presumably because of differences in diet and immune responses of individuals.

There may be a good case for further studies over a longer period of time with longitudinal measurements of antibody levels. With anti-gliadin antibodies, 12 patients had high titres $(\geq 160)$ at the start of the trial and 5 were lower after 14 days (4 placebo, 1 enzyme therapy). However in the more moderate titre range, there were just as many reductions on Enzyme therapy as there were on 
placebo. Again, further studies would seem justified with both types of antibodies.

\subsection{Effect of Age}

Splitting of the patients into 3 age groups suggested that age may be relevant to both skin symproms and/signs and production of antibodies, with older patients being the least affected by the gluten challenge. Other studies have shown that persons of any age may be affected by $\mathrm{DH}$ with peak onset in their second to fourth decade [23]. Gender may also be important but larger trials would be necessary before any conclusions could be drawn.

\subsection{Gastrointestinal Symptoms}

These types of symptoms were far less prominent than the skin features in the patients studied. There was no clear pattern between the development of skin lesions and gastrointestinal symptoms except that the majority of patients with lesions showed no gastrointestinal symptoms. All patients with intestinal symptoms showed nil to very mild skin lesions.

Based on the promising results of enzyme therapy on the clinical features of $\mathrm{DH}$, it would seem that the study has provided evidence for the deficiency of an enzyme capable of digesting gluten peptides in this disease. This clinical evidence supports the evidence that immunogenic and toxic gluten fragments cause disturbances in the small intestine, leading to tissue damage [19]. It will be desirable to carry out similar research on mucosal tissue of patients with $\mathrm{DH}$ in comparison with normal individuals, as has been done with CD. Nevertheless, enzyme therapy may be of assistance to those DH patients on a gluten-free diet who are unable to cease medication (e.g. Dapsone) completely [24] or simply as an adjunct to a gluten free diet.

Life-long gluten-free diet is established therapy for CD and DH. It allows the intestinal mucosa to recover, improves nutrient absorption and osteoporosis [25,26]. Strict dietary adherence is necessary to avoid the longterm complications, which are, principally, osteoporosis and small bowel lymphoma. However, risk of these complications diminishes very considerably in patients who are on gluten-free diet $[27,28]$. Many DH patients have difficulty in adhering to a strict gluten-free diet, allowing a useful place for adjunctive approaches such as enzyme therapy.

Enzyme therapy could provide a better alternative to dapsone. Dapsone does not bring about recovery of the intestinal mucosa and has many side-effects. The most prominent side-effects of this drug are dose-related haemolysis (which may lead to haemolytic anemia) and methaemoglobinemia [27]. About 20\% of patients treated with dapsone suffer hemolysis and the side-effect is more common and severe in those with glucose-6-phosphate dehydrogenase deficiency, leading to the dapsonecontaining antimalarial combination, Lapdap, being withdrawn from clinical use. Agranulocytosis occurs rarely when dapsone is used alone but more frequently in combination regimens for malaria prophylaxis. Abnormalities in white blood cell formation, including aplastic anemia, are rare, yet are the cause of the majority of deaths attributable to dapsone therapy. Enzyme supplement is not associated with any serious side effects, bringing its use for treatment of DH into sharp focus. This trial is a highly promising start for future studies in this area.

\section{Acknowledgements}

We gratefully acknowledge help of Professor Panlop Zeephongsekol of the Department of Mathematics and Statistics, RMIT University, Melbourne, for expert advice on the statistical methods employed The study was funded by the research projects of Medical University of Lodz: No 503/1-152-01/503-01.

\section{References}

[1] Mäki M, Collin P. Coeliac disease. Lancet 1997; 349: 1755-1759.

[2] Fry L. Dermatitis herpetiformis. In: Coeliac disease: M. Marsh, (Ed.), Oxford, UK, Blackwell Scientific Pub. 1992.

[3] Duhring L. Dermatitis herpetiformis. JAMA 1884; 3: 225-229.

[4] Caproni M, Antiga E., Melani L, Fabbri P. Italian Group for Cutaneous Immunopathology. Guidelines for the diagnosis and treatment of dermatitis herpetiformis. J Eur Acad Dermatol Venerol; 2009; 23: 633-638.

[5] Reunala T. Dermatitis herpetiformis. Clin Dermatol, 2001; 19: 728-736.

[6] Lewis HM, Renaula TL, Garioch JJ, et al. Protective effect of gluten-free diet against development of lymphoma in dermatitis herpetiformis. Br J Dermatology 1996; 3: 363-367.

[7] Puavilai S, Chutha S, Polnikorn N, et al. Incidence of anemia in leprosy patients treated with dapsone. J Med Assoc Thai. 1984; 67: 404-407.

[8] Turchin I, Barankin B. Dermatitis herpetiformis and gluten-

[9] Molberg O, Mc Adam S, Korner R. Tissue transglutaminase selectively modifies gliadin peptides that are recognized by gutderived T cells in celiac disease. Nat Med 1998; 4: 713-717.

[10] Van der Wal Y, Kooy Y, Veelen P. Cutting Edge: Selective deamidation by tissue transglutaminase strongly enhances gliadinspecific T cell reactivity. J Immunol 1998; 161: 1585-1588.

[11] Dietrich W, Ehnis T, Bauer M. Identification of tissue transglutaminase as the autoantigen of celiac disease. Nature Med 1997; 3: 797-801.

[12] Kumar V, Zane H, Kaul N. Serologic markers of gluten-sensitive enteropathy in bullous diseases. Arch. Dermatol. 1992; 128 (11): $1474-1478$.

[13] Ko CJ, Collegio OR, Moss JE, McNiff JM. Fibrillar IgA deposition in dermatitis herpetiformis - an underreported pattern with potential clinical significance. Journal of cutaneous pathology. 2010; 37: 475-477.

[14] Van L, Browning JC, Krishnan RS, Kenner-Bell BM, Hsu S. Dermatitis herpetiformis: potential for confusion with linear IgA bullous dermatosis on direct immunofluorescence. Dermatol on line Journal 2008; 14: (1), 21.

[15] Holm K, Mäki M, Savilathi E. Intraepithelial $\gamma / \delta$ T- cell receptor lymphocytes and genetic susceptibility to coeliac disease. Lancet 1992; 339: 1500-1503.

[16] Vecchi M, Crosti L, Berti E. Increased jejunal intraepitelial lymphocytes bearning $\gamma / \delta$ T-cell receptor in dermatitis herpetiformis. Gastroenterology 1992; 102: 1499-1505.

[17] Caproni M, Feliciani C, Fuligni A. Th2-like cytokine activity in dermatitis herpetiformis. Br J Dermatol 1998; 138: 242-247.

[18] Einstein WM, Brow JR, Parker F. The small intestinal mucosa in dermatitis herpetiformis. Relationship of the small intestinall lesion to gluten. Gastroenterology 1971; 60: 362-369.

[19] Cornell HJ, Stelmasiak T. A unified hypothesis of coeliac disease with implications for management of patients. Amino Acids 2007; 33: $43-49$.

[20] Cornell HJ, Macrae FA, Melny J, et al. Enzyme therapy for management of coeliac disease. Scand. J. Gastroent 2005; 40: 1304-1312.

[21] Stepniak D, Spaenij-Dekking L, Mitea C, et al. Highly efficient gluten degradation with a newly identified prolyl endoprotease: 
implications for celiac disease. Am J Physiol Gastrointest Liver Physiol 2006; 291: G621-G629.

[22] Cornell HJ, Stelmasiak T. Caricain: A basis for enzyme therapy for coeliac disease. S Afr J Sci 2011; 107: (09/10)

[23] Templet JT, Welsh JP, Cusack CA. Childhood dermatitis: a case report and review of the literature. Cutis. 2007; 80 (6): 473-476.

[24] Garioch JJ, Lewis HM, Sargent SA, Leonard JN, Fry L. 25 years' experience of a glute-free diet in the treatment of dermatitis herpetiformis. Br. J. Dermatol. 1994; 131 (4): 541-545.
[25] Gregory J, Foster K, Tyler H. The dietary and nutritional survey of British adults HMSO, London. 1990.

[26] Gajewska J, Ambroszkiewicz J, Hozyasz K. Biochemical markers of bone turnover In children with celiac disease on gluten free-diet. Med Wieku Rozwoj. 2005; 9 (4): 675-683.

[27] Fry L, Mcminn R, Cowan J. Effect of Gluten- free diet on dermatological, intestinal and haematological manifestations of dermatitis herpetiformis. Lancet 1968; i: 557-561.

[28] Fry L, Seath P, Riches D. Clearance of skin lesions in dermatitis herpetiformis after gluten withdrawal. Lancet 1973; i: 288-291. 